\title{
Article \\ Research on Factors Affecting Public Risk Perception of Thai High-Speed Railway Projects Based on "Belt and Road Initiative"
}

\author{
Sangsomboon Ploywarin 1,2 (iD, Yan Song ${ }^{1, *}$ and Dian Sun 1 (iD \\ 1 School of Economics and Management, Harbin Engineering University, Harbin 150001, China; \\ sangsombun@hotmail.com (S.P.); sundian900621@163.com (D.S.) \\ 2 International Strategy Division, Rajamangala University of Technology, Thanyaburi 12110, \\ Pathum Thani, Thailand \\ * Correspondence: songyan@hrbeu.edu.cn
}

Received: 25 April 2018; Accepted: 8 June 2018; Published: 13 June 2018

\begin{abstract}
Studies on the factors affecting public risk perception of high-speed railway projects in Thailand are very limited. The aim of this study was to assess the influencing factors of public railway project risk perception, which described the public trust degrees of government, enterprise, media and experts with a combination of variables. Therefore, the study used the widely accepted influential factors and proposed a comprehensive framework to clarify the mechanism among various factors in the public risk perception. Dataset of 675 samples was collected from Don Muang area Bangkok, Pak Thong Chai, Pak Chong, Kaengkhoi area, and Nakhon Ratchasima Province, Thailand through questionnaire. Rationality of the questionnaire was ensured through its high reliability and efficiency. The dimension hypothesis of the second-order factor was validated by confirmatory factor analysis, and the relationship among information acquisition, trust, emotion and risk perception was analyzed through the structural equation model. The results show that, within the factors that affect risk perception, the public has a more direct effect on the factors of social emotion of railway projects compared with information acquirement and the factors of trust level of each subject. This study exerts practical implications to reduce public risk perception of railway projects and promote the development of railway in Thailand.
\end{abstract}

Keywords: Thai-Sino high-speed railway project; the Belt and Road; public risk perception; affecting factors

\section{Introduction}

The International Summit Forum at Beijing in May 2017 represented the remarkable success of the contributions of the past three years of "Belt and Road Initiative". Meanwhile, it will play a greater role in the world economy. During September and October 2013, President Xi Jinping visited Central and Southeast Asian countries, where he proposed a major initiative to build the "Silk Road Economic Belt" and "21st-Century Maritime Silk Road" (referred to as "the Belt and Road Initiative"), which received a positive response from Thai government. In November 2014, when Thai Prime Minister Yasushi Akira attended APEC leaders' meeting in Beijing, he said that [1], "Thailand is exploring a path of development which meets its own national realities and hopes to make exchanges and deepen cooperation with China. With the help of 'the Belt and Road Initiative' in particular, Thai will promote agriculture, railway cooperation and regional interconnectivity, expand the export of its own agricultural products to China, facilitate non-governmental exchanges as well as strengthen personnel training". In December the same year, Prime Minister Paryuth Chan-ocha visited China again and reiterated that Thailand is willing to actively participate in "the Belt and Road Initiative" 
proposed by President Xi Jinping. Thailand would deepen cooperation in the fields of railways, communications and tourism; promote regional interconnectivity; and march to the goal of a free trade zone in Asia-Pacific region [2]. "The belt and Road initiative" is both a strategic opportunity and a realistic challenge for Thai-Sino relations.

Because of the decrease in Thailand's GDP since 2014, Thai government was eager to pour driving force into Thailand's weak economy through high-speed rail project and other infrastructure. In April 2016, the Thai National Railway Administration approved to construct two new railroad tracks, with a total investment of 143.5 billion baht (about 4.1 billion US dollars), which showed that the railway development has entered a new stage after the stagnation for up to half a century. The negotiations for Thai-Sino High-speed Railway project lasted for three years and plans to begin building the longest Bangkok-Nakhon Ratchasima section in 2017 were made. The reasons for such a long negotiation were the differences in funds, the design of blueprints, and the delay in the railway development, which raised suspicion of the railway project and conflicting emotions among Thai people. Many other experiences in large-scale projects such as the Thailand Coal Power Plant project showed that the public's attitude towards the project depended on their subjective awareness of the project, that is, risk perception, rather than scientific and rational judgment. Thus, it is necessary to propose a public risk perception of high-speed railways in Thailand.

Scholars have studied the influencing factors of risk perception from different aspects. It is common to analyze the impact factors of risk perception in large-scale projects. Qualitative analysis is widely used compared to quantitative empirical research methods. In the process of railway project safety management, the judgments and reactions of people can be investigated when people assess the potential risks of railway projects [3]. Therefore, this paper constructs the high-order variable trust to describe the overall trust level of the government, experts, media and enterprises from the public. It also establishes a theoretical framework for the impact mechanism of risk communication, information acquisition, social emotion and trust on the public perception of risk. Structural equation and hierarchical regression analysis method were used to analyze the influence of variables to reduce public opposition to Thailand high-speed rail projects and provide useful suggestions for the administrative department to formulate relevant policies and regulations of railway projects.

\section{Theoretical Background and Research Hypotheses}

Study of the influencing factors of public risk perception includes not only the characteristics of risk itself and the sources of information, but also the analysis of trust and emotion as well as value orientation [4-7]. Elsewhere, scholars have explored the influencing factors for risk perception from different perspectives. Lupton [8] suggested that the level of public risk knowledge, risk perceptions, and the acceptability of risks depended on the social environment in which the public was located. Different social backgrounds and cultural heritage formulate different public understanding for risk and the formation of risk perception is more a process of social development. Connor et al. [9] found that in the United States of America the knowledge of risk, risk assessment and behavioral intention are all different, which directly affects the public acceptance and judgment for the risk. The results showed that the factors influencing risk judgment not only include the knowledge reasons discussed by predecessors, but also other reasons such as politics, economy, environment, culture and family relations. The public perception of risk will take all characteristics affecting public risk perception which is important in the index system of major project stability evaluation. Similarly, various psychological factors should be considered in the public risk perception of railway project.

According to the particularity of Thailand high-speed railway project and the harmful consequence that technical backwardness may bring, the technology acceptability model [10] put forward by scholars was used. The model draws on the important role of trust factors and combines the widely-accepted emotion factors in the field of risk perception. This paper integrates the influential factors which have been widely accepted by scholars and attempts to adopt a comprehensive framework to clarify the mechanism among various factors in the public risk perception. 


\subsection{Important Role of Trust}

Trust is the main factor that affects public risk perception [11]. Previous research, whether in terms of the model building or the empirical conclusion, reflects the inverse relationship between trust factor and risk perception [12]. Media is a major link in the process of social amplification of risk and a main way for people to obtain information [13]. When people do not have sufficient knowledge of the risks, the public often takes information directly from the media. Thus, the media plays an important role in the public's risk perception in Thailand railway project. From the point of the related responsibility of the railway project in Thailand, nuclear power plant research experience [14] is applied to study the effect of public trust factor in terms of the media, the government, the experts and the enterprises.

Earle and Cvetkovich [15] pointed out that public decision-making and judgments are often guided by social trust because of the lack of knowledge. They prefer to choose experts based on trust, rather than making rational judgments on unfamiliar risks. Studies by Siegrist and Cvetkovich show that, when public knowledge of risk programs is scarce, public judgments about risk and income will depend on social trust [16]. In the field of power plant, a lot of research shows that trust has a significant effect on the perception of specific technologies [17-20]. Compared with the public, experts have a comprehensive knowledge and information about technology which can objectively evaluate the feasibility of technology [21]. However, in Thailand's social realities, experts cannot make concerted agreement on the railway project due to the reluctance to accommodate varied opinions. Hence, the credibility of experts is compromised, resulting in increased public awareness of the railway risk and the assessment of risk is far higher than the expert evaluation.

Based on the above analysis, this paper puts forward the following hypotheses:

Hypothesis H1: Trust from the public is a high-order variable of the government, experts, media and enterprises.

Hypothesis H2: Trust has an inverse correlation with the public perception of risk in railway projects.

Hypothesis H3: Trust and social emotion are inversely related, that is, the higher the degree of trust, the more positive the mood, and vice versa.

\subsection{Social Sentiment and Public Perception of Risk}

Previous studies show that public choice behavior in crisis situations is influenced by perceptions of risk [22-24]. A too high-risk perception will lead to an overreaction of the public, resulting in unnecessary irrational behavior. The difference of public risk perception often influences the effect of response measures of governmental crisis. Loewenstein et al. [25] established the emotional hypothesis which pointed out that risk perception depends not only on rational cognitive judgment, but also on the mood of decision makers. The idea that emotion has a significant impact on risk perception has been widely accepted by scholars. Studies have shown that people with positive emotions are at a lower risk level than those with social emotions. Due to the particularity of railway projects, its construction will take up large amount of land which will naturally arouse public anxiety and fear. Therefore, it is necessary to explore the impact of social emotion on project risk perception.

Based on the above analysis, this paper puts forward the following hypothesis:

Hypothesis H4: Social emotion is positively correlated with the public risk perception of the railway project.

\subsection{Information Acquisition}

Numerous studies have shown that the dissemination of information is very important to the public's risk perception in risk events. The methods of sourcing for information and the presentation 
of information content will greatly influence and even determine the public's risk perception of the event [26].

Midden [27] suggested that trust depends on the quality of information, the source of the information, and the organization and performance of the institution in the public risk perception. The public trust in government mainly comes from the historical performance and current behavior of the government's ability which is the long-term construction process. Especially, the effectiveness of the government and experts' risk communication in each crisis events will directly affect the trust level of the public. Therefore, the acquisition of information is very important for building trust in railway projects.

Based on the above analysis, this paper puts forward the following hypotheses:

Hypothesis H5: There is a positive correlation between information acquisition and trust.

Hypothesis H6: Information acquisition is positively correlated with social emotion.

\subsection{Technology Risk and Public Risk Perception}

Based on Baker's analysis of the ubiquity of risk, the uncertainty of modern science technology, the failure of national society management, and the technological risk of the expansion of globalization have aroused general risk awareness due to the serious consequences. However, there is no significant consistency between the actual risk and the perception of risk in risk event. The risk communication expert Sandman has introduced the concept of "anger" to explain the sources of differences between technology risk and risk perceptions. As a result, public outrage can result in a cognitive amplification of actual risks. In other words, for those projects or events with relatively low technical risk, they will be considered as high-risk projects or events if they encounter outrageous crowd. In the Thai-Sino high-speed railway project, the Chinese railway technology will be adopted. Although China's high-speed railway has developed rapidly in recent years, Thai people have little knowledge about high-speed railway, because of the stagnation in the development of Thai railway in recent decades, which will inevitably raise suspicion of China high-speed railway technology.

Based on the above analysis, this paper puts forward the following hypothesis:

Hypothesis H7: The technical risk is positively correlated with the public risk perception of railway project.

\subsection{Conceptual Model}

A conceptual model of the impact factors in high-speed railway project risk perception can be developed based on the above analysis, as shown in Figure 1.

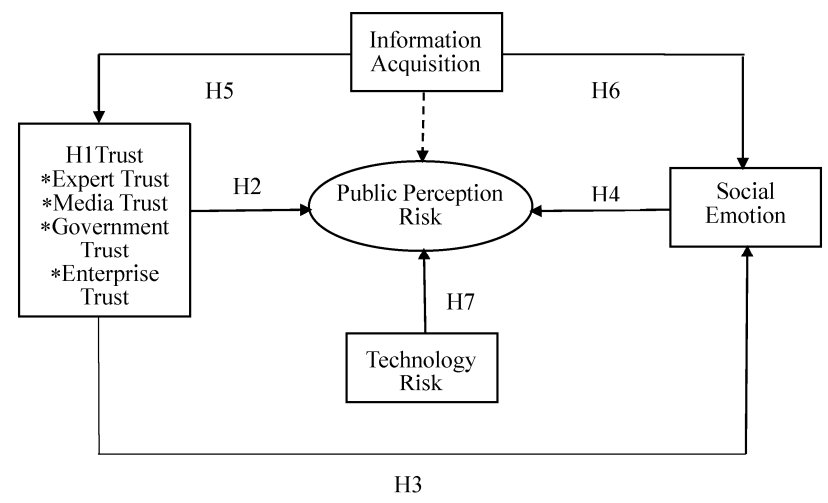

Figure 1. Conceptual model of influencing factors of risk perception in high-speed railway projects. 


\section{Research and Design}

The variables data for this study were collected and counted through a wide range of questionnaires. Rationality of the questionnaire was ensured through its high reliability and efficiency. The dimension hypothesis of the second-order factor was validated by confirmatory factor analysis, and the relationship between information acquisition, trust, emotion and risk perception was analyzed through the structural equation model.

\subsection{Questionnaire Design and Variable Processing}

The operational definition and measure index of the variable were sorted. Combined with the construction of railway projects, the measuring scale of four latent variables of risk perception, trust, emotion and information were designed, and the variables were measured using a five-point Likert scale, from 1 to 5 representing: 1, "very disagree"; 2 , "disagree"; 3 , "general"; 4, "consent"; and 5, "very agreeable". For the negative effect involved in the questionnaire, the negative score was set for the needs of the research.

The selection of indicators and questionnaires was discussed in interviews with 12 engineering experts at a Thai university, and the scale was revised and improved. Before the formal investigation, 60 college students were selected to carry out a small-scale preliminary survey. According to the recommendations, the problems in the questionnaire were clarified, which enhanced its operability. The revised scale is shown in Table 1.

Table 1. Sample population description analysis.

\begin{tabular}{cccc}
\hline Statistical Content & Category & Sample Number & Proportion \\
\hline \multirow{2}{*}{ Gender } & Male & 301 & $44.59 \%$ \\
& Female & 374 & $55.41 \%$ \\
\hline \multirow{4}{*}{ Age } & Under 20 & 88 & $13.03 \%$ \\
& $20 \sim 30$ & 196 & $29.04 \%$ \\
& $30 \sim 40$ & 167 & $24.74 \%$ \\
& $40 \sim 50$ & 113 & $16.74 \%$ \\
& $50 \sim 60$ & 87 & $12.89 \%$ \\
Education & 60 and above & 24 & $3.56 \%$ \\
& Junior High School & 132 & $19.56 \%$ \\
& High School & 154 & $51.56 \%$ \\
& Undergraduate & 348 & $8.94 \%$ \\
& Postgraduate & 41 & $6.07 \%$ \\
\hline \multirow{5}{*}{ Occupation } & Party and Government Officer & 49 & $7.26 \%$ \\
& Institution Officer & 94 & $13.93 \%$ \\
& Enterprise officer & 146 & $21.63 \%$ \\
& Professional and Technical & & \\
& Personnel (Teachers, Doctors, & 67 & $9.93 \%$ \\
& Engineers) & & \\
& Student & 219 & $32.45 \%$ \\
& Retired & $4.30 \%$ & $6.65 \%$ \\
& Freelance & 26 & $3.85 \%$ \\
\hline
\end{tabular}

\subsection{Overall Sample Description and Data Collection}

According to the analysis of 675 effective questionnaires, the overall description of the sample was summarized and analyzed which includes gender, age, education and occupation. The results of the overall description of the samples are shown in Table 1.

Because the current research does not involve regional differences, the study analyzed the influencing factors of railroad project risk perception from the individual microcosmic angle. 
This research adopted the quantitative investigation method to obtain the data. According to the first-phase in Thai-Sino high-speed railway project, Bangkok and Nakhon Ratchasima mansion would be connected with a length of $252.5 \mathrm{~km}$ and the design speed of $250 \mathrm{~km} / \mathrm{h}$.

Data were collected through questionnaire from 16 August 2017 to 25 December 2017 in Bangkok and Nakhon Ratchasima mansion. During the period of this investigation, 800 questionnaires were issued and 728 questionnaires were collected, among which 675 questionnaires were effective, and the effective recovery rate was $92.71 \%$. From the gender perspective, the male and female proportions of the sample were almost the same: 374 were female $(55.41 \%)$, and 301 were male (44.59\%). From the age perspective, 88 were $<20$ years old $(13.03 \%), 196$ were $20-30$ years old $(29.04 \%), 167$ were $30-40$ years old ( $24.74 \%), 113$ were $40-50$ years old $(16.74 \%), 87$ were $50-60$ years old $(12.89 \%)$, and 24 were $>60$ years old (3.56\%). For the level of education, 132 had junior high school education or below, 154 had college/undergraduate education, 348 had graduate education, and 41 had postgraduate education or above. From the professional point of view, there were students, business staff and institutions staff: 219 from students, 146 from enterprise staff and 94 from units which accounted for $68.01 \%$. Professional and technical personnel and the number of party workers were relatively large, accounting for $9.93 \%$ and $7.26 \%$, respectively. Freelancers, farmers and others accounted for $6.65 \%, 4.3 \%$, and $3.85 \%$, respectively. From two urban population characteristics, the sample had a good representation, and the data could meet the needs of further research.

\subsection{Reliability of Scale and Analysis of Validity}

Reliability and validity analysis are the precondition of model evaluating. This research carried out the screening of the questionnaire, and then selected data were input to SPSS23.0 and AMOS21.0 statistic software (see Table 2). Cronbach's $\alpha$ was used to evaluate the reliability of data. The Cronbach's $\alpha$ value of the whole scale is $0.994(>0.70)$. The $\alpha$ value of the corresponding component table of each variable is also greater than 0.7 which shows that the scale has high reliability. Validity analysis includes two parts: content validity and structure validity. For content validity, the problem of measuring variables is obtained based on analysis and collation of domestic literature and completed through the discussion and confirmation with experts as well as small sample to be modified and tested. Hence, the variables have good content validity. As for structural validity, by applying the factor analysis method in statistical analysis which can test the factor load of the variables corresponding to each index, each topic has a good factor load on its corresponding factors which reflects the relative importance of the factor load in public factors. $p \leq 0.01$ indicated that it has strong statistical significance and sound convergence validity. Through the above results, each topic can clearly explain the corresponding variables, so the scale has good structural validity. For sample and data test results, the KMO (Kaiser-Meyer-Olkin) value is 0.945 and Bartlett's Spherical test significance is 0.000 which means the questionnaire data are suitable for application factor analysis. Through the correlation coefficient range of the variable index in Table 2, we can see that the variable index correlation coefficient does not contain the value 1 , and the corresponding $p$ value is significant $(p<0.01$ or 0.05$)$ which indicates that the validity of the scale is verified by statistics. 
Table 2. Variable reliability and validity analysis.

\begin{tabular}{|c|c|c|c|c|}
\hline Variable & Item & Factor Loading & Cronbach's $\alpha$ & $\begin{array}{l}\text { Variable Index Correlation } \\
\text { Coefficient (Range) }\end{array}$ \\
\hline \multirow{8}{*}{$\begin{array}{l}\text { Information } \\
\text { Acquisition (IA) }\end{array}$} & Railway Accident Information (IA1) & 0.680 & \multirow{8}{*}{0.933} & \multirow{8}{*}{$0.523-0.597$} \\
\hline & Railway Safety Information (IA2) & 0.448 & & \\
\hline & Reducing Railway Hazard & 0.480 & & \\
\hline & Information (IA3) & 0.480 & & \\
\hline & Railway Project Operation Supervision & & & \\
\hline & Support Information (IA4) & 0.557 & & \\
\hline & Railway Transportation Efficiency & 0.309 & & \\
\hline & Guarantee Information (IA5) & 0.309 & & \\
\hline \multirow{5}{*}{$\begin{array}{l}\text { Risk Perception } \\
\text { (RP) }\end{array}$} & Visibility (RP1) & 0.960 & \multirow{5}{*}{0.975} & \multirow{5}{*}{$0.521-0.644$} \\
\hline & Frightening (RP2) & 0.662 & & \\
\hline & Possibility (RP3) & 0.604 & & \\
\hline & Seriousness (RP3) & 0.608 & & \\
\hline & Controllability (RP4) & 0.962 & & \\
\hline \multirow{6}{*}{ Social Emotion (SE) } & Unconvinced (SE1) & 0.849 & \multirow{6}{*}{0.973} & \multirow{6}{*}{$0.507-0.654$} \\
\hline & Worry (SE 2) & 0.875 & & \\
\hline & Tense or Anxious (SE3) & 0.875 & & \\
\hline & Discontent or Dislike (SE4) & 0.477 & & \\
\hline & Scared or Frightened (SE5) & 0.855 & & \\
\hline & Anger (SE6) & 0.888 & & \\
\hline \multirow{4}{*}{$\begin{array}{l}\text { Technology Risk } \\
\text { (TR) }\end{array}$} & Technical Capability (TR1) & 0.854 & \multirow{4}{*}{0.982} & \multirow{4}{*}{$0.566-0.671$} \\
\hline & Risk Control Ability(TR2) & 0.854 & & \\
\hline & System Technical Performance (TR3) & 0.791 & & \\
\hline & Technology Risk Management (TR4) & 0.655 & & \\
\hline \multirow{4}{*}{ Expert Trust (ExT) } & Evaluation Ability (ExT1) & 0.749 & \multirow{4}{*}{0.984} & \multirow{4}{*}{$0.575-0.691$} \\
\hline & Speech Authenticity (ExT2) & 0.709 & & \\
\hline & Accountability (ExT3) & 0.633 & & \\
\hline & Reliability (ExT4) & 0.672 & & \\
\hline \multirow{3}{*}{ Media Trust (MT) } & Reporting Authenticity (MT1) & 0.778 & \multirow{3}{*}{0.947} & \multirow{3}{*}{$0.540-0.691$} \\
\hline & Report Timely (MT2) & 0.745 & & \\
\hline & Responsibility (MT3) & 0.772 & & \\
\hline \multirow{5}{*}{$\begin{array}{l}\text { Government Trust } \\
\text { (GT) }\end{array}$} & Political Reliability (MT4) & 0.602 & \multirow{5}{*}{0.985} & \multirow{5}{*}{$0.478-0.551$} \\
\hline & Possibility of Supervision and & 0.564 & & \\
\hline & $\begin{array}{l}\text { Management System (GT1) } \\
\text { Feasibility of Decision Making (GT2) }\end{array}$ & 0.964 & & \\
\hline & $\begin{array}{l}\text { Feasibility of Decision Making (GT2) } \\
\text { Emergency Management }\end{array}$ & 0.941 & & \\
\hline & Practicability (GT3) & 0.672 & & \\
\hline \multirow{3}{*}{$\begin{array}{l}\text { Enterprise Trust } \\
\text { (ET) }\end{array}$} & $\begin{array}{c}\text { Managerial Competence and Empirical } \\
\text { Reliability (ET1) }\end{array}$ & 0.728 & \multirow{3}{*}{0.976} & \multirow{3}{*}{$0.484-0.569$} \\
\hline & Rationality of Decision Process (ET2) & 0.762 & & \\
\hline & Fund Reliability (ET3) & 0.778 & & \\
\hline
\end{tabular}

\section{Verification and Modification of Model}

\subsection{Trust Second-Order Factor Model}

To test the measurement rationality of the observational variables, the study used AMOS6 to analyze confirmatory factor of each variable. The test trust factor is the higher-order factor assumption by the public composed by four dimensions including experts, media, government and enterprise. An overall model suitability test for second-order confirmatory factor analysis is between 2 and 5 . The smaller is the numerical value, the better is the fitting degree of the model. Incremental Fit Index (IFI), Normed Fit Index (NFI), Comparative Fit Index (CFI), and Goodness of Fit Index (GFI) are more than 0.90. Root Mean Square of approximation (RMSEA) is less than 0.05 which should be less than 0.08 (Table 3). To verify the dimensions, polymerization validity, difference validity of trust measurement, and the reliability of second-order factor construction, this study constructed four correlative first-order factors formed by trust items and high-order second-order factor models formed by the corresponding first-order factors (see Figure 2). As shown in Table 3, the associated first- and second-order factor models are less than 5, and the two RMSEA are less than 0.08. IFI, NFI, CFI, and GFI values are greater than 0.9 . The model fitted the corresponding criteria. The factor load of trust is above 0.5 , and the path of the item to the factor is very significant, which shows that the public has excellent polymerization validity for the structure model. To further verify that the trust factor 
dimension is a higher-order factor, we should prove the rationality of the second-order factor not only through the comparison value, but also the value of the goal coefficient $T$. The value of the target coefficient $\mathrm{T}$ is the ratio of chi square value about the low-order factor model and the higher-order factor model [28]. The closer is the T value to 1, the more reasonable is the higher-order factor. When the $\mathrm{T}$ value is higher than 0.90 , the higher-order factor model can effectively explain the correlation between the lower-order factor [29]. Here, the target coefficient $\mathrm{T}=38 / 40=0.95$ indicates that the trust factor interprets $95 \%$ relationship of four dimensions feature and the second-order factor loads are very significant. Therefore, assuming that $\mathrm{H} 1$ is validated, the trust is a higher-order variable composed of the public to the media, government, experts, and enterprises. It is more reasonable to make further investigation on the public perception of trust with different subjects. In the four trust dimensions, the government trust has the most obvious contribution to the trust factor according to the factor load coefficient, followed by the trust of the railway enterprise, media, and finally the expert trust. This shows that the importance of different dimensions is different in the consideration of the relationship between trust factors and other variables. For instance, the degree of trust in the government is significantly higher than others, that is, when raising public confidence in government (government credibility), the role of trust factors can be significantly improved.

Table 3. Fitting indexes of each factor model $(n=675)$.

\begin{tabular}{ccccccccc}
\hline Model & Chi-Square & df & Chi-Square/df GFI & RMSEA & CFI & AGFI & NFI \\
\hline Associated First-order Factor & 139.337 & 71 & 1.962 & 0.971 & 0.038 & 0.949 & 0.958 & 0.903 \\
second-order Factor & 159.238 & 73 & 2.181 & 0.939 & 0.058 & 0.955 & 0.925 & 0.934 \\
\hline
\end{tabular}
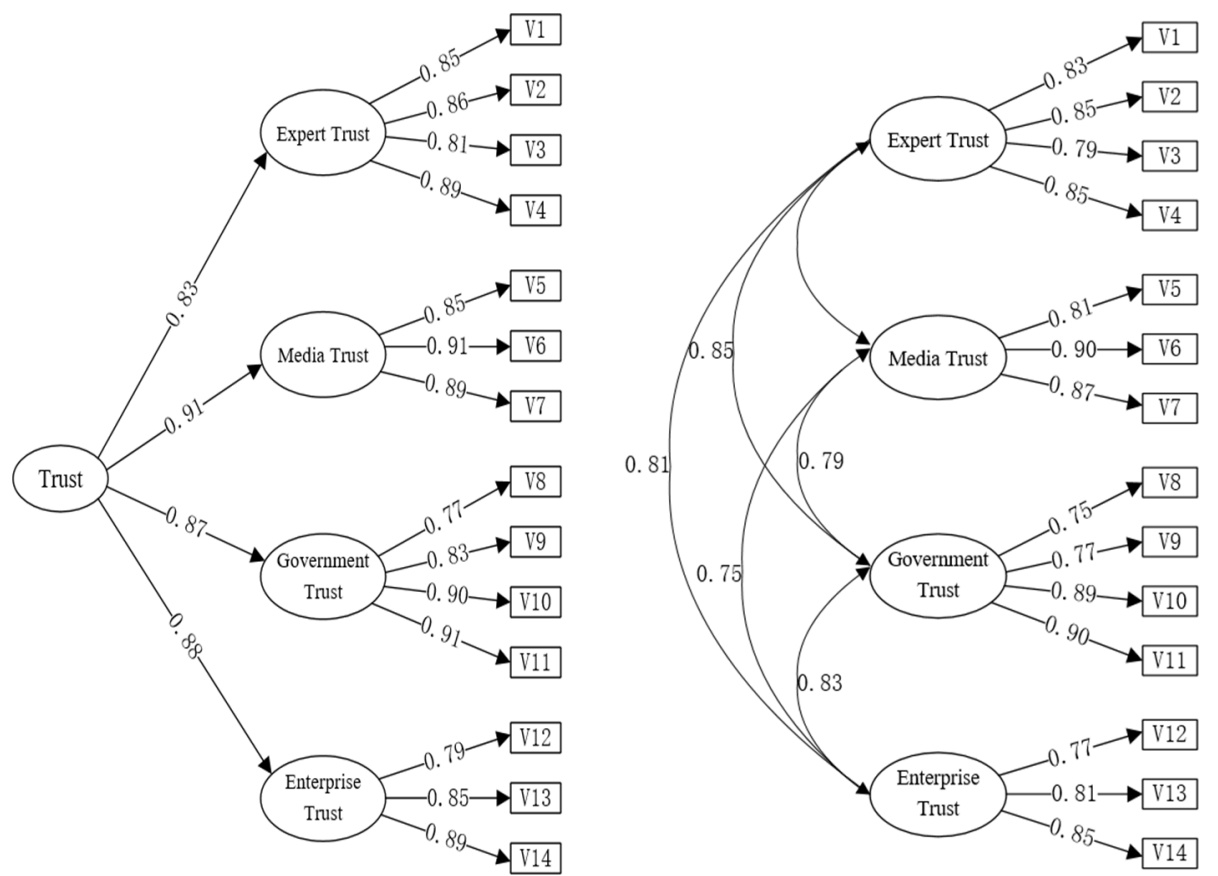

Figure 2. Confidence analyses of second-order factor confirmation.

\subsection{Inspection and Correction of the Whole Model}

Based on the above analysis, the trust variable is a higher-order variable composed of four dimensions of media trust, government trust, expert trust and enterprise trust. The high dimension brings great inconveniences to the calculation, and there may be complex nonlinear correlation between each index. In the past, most studies used the average value of the measurement index of each variable to substitute each variable, which could lead to the deviation of the estimation result. Therefore, the weighted arithmetic mean was used to calculate the five-dimension variables, which are the five 
measurements of trust. The weights are determined by the measurement of the variables and the load factors of potential variables.

After confirming the reliability and validity of the measurement model, the AMOS6 software was used to analyze the path based on the maximum likelihood estimation method. The model was modified preliminarily according to the modification indices of the model output to enhance the fitting of the model. By modifying the model, the fitting result of the whole model is shown in Figure 3. The $\chi^{2} / d f$ value is $1.779<5$, RMSEA is $0.34<0.08$. CFI is 0.944 and Adjusted Goodness of Fit Index (AGFI) is 0.943 which is greater than 0.9 (see Table 4). Parsimonious Normed Fit Index (PNFI) is 0.785, which fits well. Thus, the model reached an acceptable level. Based on the criterion of fitting, the model was tested and the results are shown in Table 5.

Table 4. Comparison of fitting indexes of each model.

\begin{tabular}{ccccccccc}
\hline Model & Chi-Square & df & \multicolumn{2}{c}{ Chi-Square/df GFI } & RMSEA & CFI & AGFI & NFI \\
\hline Original Model & 1477.009 & 202 & 7.312 & 0.863 & 0.097 & 0.536 & 0.829 & 0.504 \\
Modified Model & 352.311 & 198 & 1.779 & 0.955 & 0.034 & 0.944 & 0.943 & 0.882 \\
\hline
\end{tabular}

Table 5. Parameter estimation results of the modified model.

\begin{tabular}{|c|c|c|c|c|c|c|c|}
\hline & & & Estimate & S.E. & C.R. & $p$ & Label \\
\hline Trust & $<-$ & Information Acquisition & 0.271 & 0.125 & 1.923 & 0.016 & par_1 \\
\hline Social Emotion & $<-$ & Information Acquisition & 0.315 & 0.108 & 2.925 & 0.002 & par_3 \\
\hline Social Emotion & $<-$ & Trust & 0.315 & 0.108 & 2.925 & 0.002 & par_6 \\
\hline Perception Risk & $<-$ & Information Acquisition & 0.314 & 0.119 & 2.628 & 0.031 & par_2 \\
\hline Perception Risk & $<-$ & Trust & 0.183 & 0.105 & 1.742 & 0.082 & par_4 \\
\hline Perception Risk & $<-$ & Social Emotion & 0.372 & 0.174 & 2.965 & $* * *$ & par_5 \\
\hline Perception Risk & $<-$ & Technology Risk & 0.355 & 0.150 & 3.132 & $* * *$ & par_23 \\
\hline $\mathrm{S} 1$ & $<-$ & Information Acquisition & 1.000 & & & & \\
\hline $\mathrm{S} 2$ & $<-$ & Information Acquisition & 0.478 & 0.201 & 2.376 & 0.017 & par_7 \\
\hline S3 & $<-$ & Information Acquisition & 0.465 & 0.220 & 2.115 & 0.034 & par_8 \\
\hline $\mathrm{S} 4$ & $<-$ & Information Acquisition & 0.573 & 0.219 & 2.616 & 0.009 & par_9 \\
\hline S5 & $<-$ & Information Acquisition & 0.146 & 0.108 & 1.353 & 0.176 & par_10 \\
\hline S6 & $<-$ & Trust & 1.000 & & & & \\
\hline S7 & $<-$ & Trust & 0.020 & 0.084 & 0.237 & 0.812 & par_11 \\
\hline S8 & $<-$ & Trust & 0.920 & 0.223 & 4.118 & $* * *$ & par_12 \\
\hline S9 & $<-$ & Trust & 0.274 & 0.069 & 3.988 & $* * *$ & par_13 \\
\hline S10 & $<-$ & Perception Risk & 1.000 & & & & \\
\hline S11 & $<-$ & Perception Risk & 1.100 & 0.160 & 6.862 & $* * *$ & par_14 \\
\hline $\mathrm{S} 12$ & $<-$ & Perception Risk & 1.344 & 0.177 & 7.584 & $* * *$ & par_15 \\
\hline S13 & $<-$ & Perception Risk & 0.850 & 0.129 & 6.594 & $* * *$ & par_16 \\
\hline S14 & $<-$ & Perception Risk & 0.790 & 0.134 & 5.901 & $* * *$ & par_17 \\
\hline S15 & $<-$ & Social Emotion & 1.000 & & & & \\
\hline S16 & $<-$ & Social Emotion & 1.811 & 0.389 & 4.838 & $* * *$ & par_18 \\
\hline S17 & $<-$ & Social Emotion & 1.547 & 0.341 & 4.934 & $* * *$ & par_19 \\
\hline $\mathrm{S} 18$ & $<-$ & Social Emotion & 0.843 & 0.252 & 3.350 & 0.003 & par_20 \\
\hline S19 & $<-$ & Social Emotion & 0.636 & 0.244 & 2.612 & 0.009 & par_21 \\
\hline S20 & $<-$ & Social Emotion & 0.021 & 0.050 & 0.414 & 0.679 & par_24 \\
\hline $\mathrm{S} 21$ & $<-$ & Technology Risk & 1.000 & & & & \\
\hline $\mathrm{S} 22$ & $<-$ & Technology Risk & 1.605 & 0.561 & 4.890 & $* * *$ & par_22 \\
\hline $\mathrm{S} 23$ & $<-$ & Technology Risk & 0.791 & 0.231 & 4.631 & $* * *$ & par_25 \\
\hline $\mathrm{S} 24$ & $<-$ & Technology Risk & 0.655 & 0.145 & 3.547 & $* * *$ & par_26 \\
\hline
\end{tabular}

Notes: Standard errors in indicates. ${ }^{* * *} p$ value is less than 0.001 . 


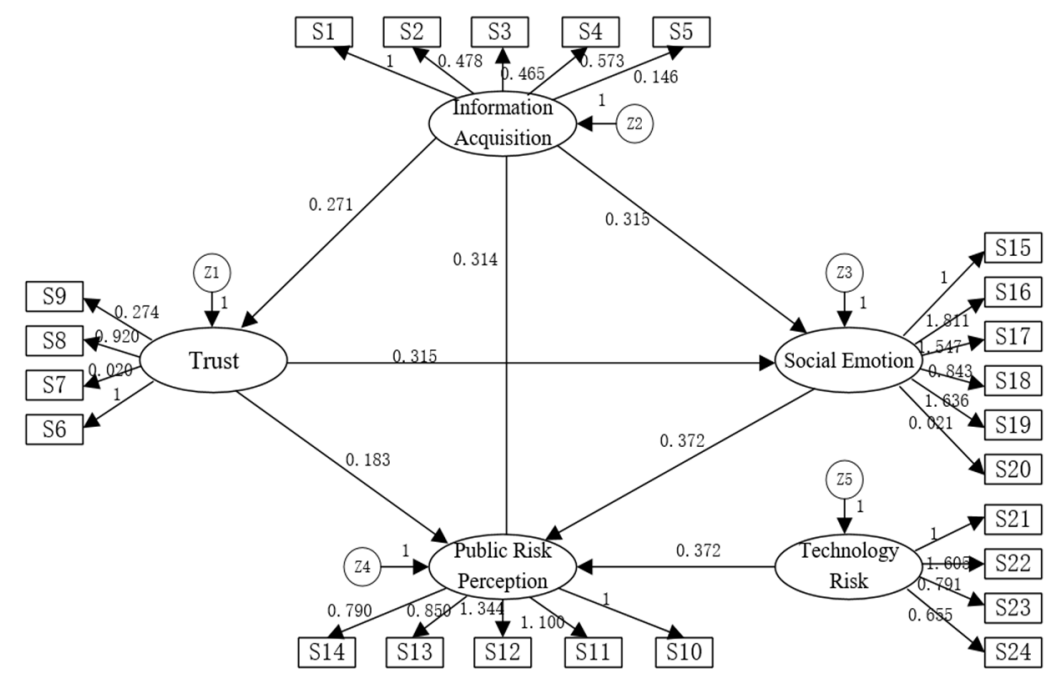

Figure 3. Overall model.

Based on Figure 3, it is obvious that Information acquisition has a significant and positive effect on Trust $(b=0.271, p=0.016)$, Social emotion $(b=0.315, p=0.002)$ and Public Risk Perception $(b=0.314$, $p=0.031)$. Thus, $\mathrm{H} 1, \mathrm{H} 5$, and $\mathrm{H} 6$ are accepted, while $\mathrm{H} 2$ is not $(\mathrm{b}=0.183, p=0.082)$. If the direct path between trust and risk perception, information acquisition and social emotion is set to be freely evaluated, the chi square value will be greatly reduced. Then, the fitting degree of the model and the corresponding parameter estimation value will be improved. To improve the data fitting of the existing model and to find the potential optimal model, we construct the competition model by comparing their fitting.

\subsection{Relationship among Social Emotion, Trust and Risk Perception}

Public trust and social sentiment are relevant. From the above path analysis, it can be concluded that social emotion has a significant positive effect on the public perception of risk $(b=0.372)$, but trust has no significant effect $(b=0.183, p=0.082)$, which contradicts with the hypothesis of this article. Then, it is necessary to analyze their relationship. Theoretically, trust can serve as mediation variable as well as mediate variable. The degree of public trust in related subjects will change the impact of social sentiment on risk perception. When the public extremely trusts government decision-making, the project risk perception of railways will not be high even if there is a certain fear of railway projects. On the contrary, the lower is the degree of trust, the greater is the impact of social emotions. On the other hand, the public's social sentiment towards the railway project will affect the public's trust, and the degree of trust will have a certain impact on public perception of risk. Therefore, it is necessary to do further analysis to explore the role of trust.

According to the test steps to adjust variable and intermediary variable proposed by Wen Zhonglin [30], the score of latent variable is centralized. The effect by multicollinearity is eliminated, and the relationship between variables and the moderating effect of trust are established by the multi-level analytic hierarchy process. The first step is to establish a regression model with risk perception as the dependent variable, and trust and social emotion as the independent variable in Model 1. The second step is to add the product of trust and social emotion as the independent variable in Model 1, and then form Model 2. The concrete regression results (see Table 6 for details).

In Models 1 and 2, the correlation coefficient between social emotion and public perception of risk is positive, so the social emotion will have positive effect on public risk perception considering the main effect variable and adjusting the variable in a single or simultaneous way. With the introduction of the intersection of trust and social emotion, the explanatory ability of Model 2 has been improved compared to Model 1 (the change of $R^{2}$ is about $7 \%$ ), which suggests that the moderating effect of trust 
is conducive to a more comprehensive explanation to the process of social emotion. The regression coefficient of trust and social emotion is positive which shows that the moderating effect of trust is significant. With the increase of public trust, the influence of social mood on public risk perception level will be reduced (see Figure 4).

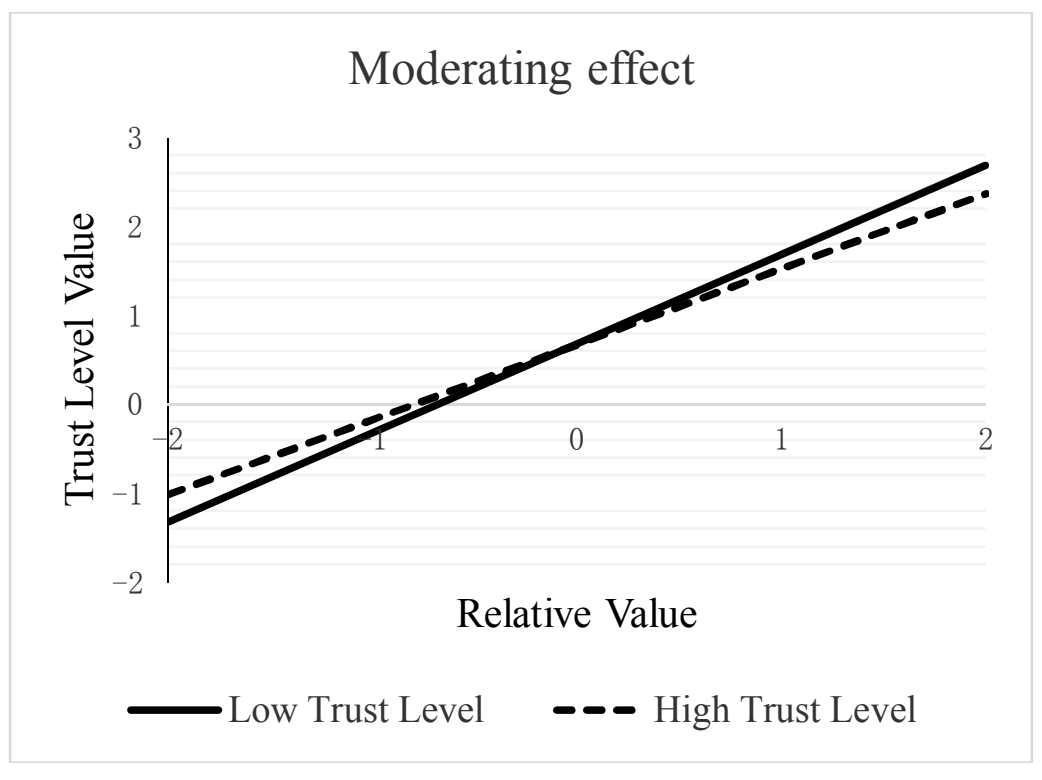

Figure 4. The moderating effect of trust level.

Table 6. Results of hierarchical regression analysis.

\begin{tabular}{cccc}
\hline & Dependent Variable & \multicolumn{2}{c}{ Public Perception Risk } \\
\cline { 3 - 4 } & & Model-1 & Model-2 \\
\hline Intercept Term & Trust & -0.003 & -0.853 \\
\hline \multirow{2}{*}{ Independent Variable } & Social Emotion & $0.253^{* *}$ & $0.266^{*}$ \\
& Trust $\times$ Social Emotion & & $0.923^{* *}$ \\
& $\mathrm{R}^{2}$ & 0.057 & $-0.014^{* *}$ \\
\hline & $\Delta \mathrm{R}^{2}$ & & 0.063 \\
& & & $0.007^{*}$ \\
\hline
\end{tabular}

Notes: Standard errors in indicates. ${ }^{*}, * *: 0.1$ and 0.05 , respectively.

\section{Conclusions}

This study aimed to assess the influencing factors of public railway project risk perception and described the trust degree of public to government, enterprise, media and experts with a combination of variables. Structure equation model and hierarchical regression analysis method were used to explore the mechanism of trust, information acquirement and social emotion of the public perception of risk. The results show that, among the factors that affect risk perception, the public has a more direct influence on the factors of social emotion of railway projects compared with information acquirement and the factors of trust level of each subject. This research has practical significance to reduce the public's perception of the risk in railway projects. The policy-making departments should popularize and educate about relevant railway related knowledge, reduce the public's anxiety, and raise attention to the public emotion factor. For instance, different strategies are formulated according to the differences of public mood characteristics at different levels. Then, the risk perception level of the public can be directly reduced. On the other hand, the serious consequences of railway accidents in the past have brought a shadow to the people around the world. If the government 
departments want to improve the public's social mood, they must pay attention to the promotion of their own credibility, and promote the ability of media, enterprises and experts to reduce negative impact brought by other Thai railway construction accidents.

The significant effect of information acquisition factors on the level of trust provided the possibility to raising public confidence in the media, government, experts and enterprises. The Thai government should improve not only the release mechanism of railway project information and the transparency of project construction information, but also the information mechanism of railway project risk communication so that the public can better understand railway technology and consequently the public's trust level to the related subjects can be raised.

Supplementary Materials: The following are available online at http:/ /www.mdpi.com/2071-1050/10/6/1978/ s1.

Author Contributions: S.P. and Y.S. conceived and designed the research questions, the conceptual model, the questionnaire and the methodology. S.P. collected and analyzed the data. Y.S. revised the paper. All authors read and approved the final manuscript.

Funding: The study was supported by the Chinese National Nature Science Foundation (Grant No. 71771061) and the Major Strategic Research Plan of Harbin Engineering University (Grant No. HEUCFW170903).

Conflicts of Interest: The authors declare no conflict of interest.

\section{References}

1. Xinhua News Agency. Xi Jinping meets with Prime Minister of Thailand, Ba Yu. Xinhua, 9 November 2014.

2. Xinhua News Agency. Xi Jinping meets with Prime Minister of Thailand, Ba Yu. Xinhua, 23 December 2014.

3. Xie, X.F. Several psychological problems in risk studies. Psychol. Sci. 1994, 2, 104-108.

4. Cox, D. Risk Handling in Consumer Behavior: An Intensive Study of Two Cases. In Risk-Taking and Information Handling in Consumer Behavior; Harvard University Press: Boston, MA, USA, 1967; pp. 34-81.

5. Starr, C. Social Benefit versus Technological Risk. Science 1969, 165, 1232-1238. [CrossRef] [PubMed]

6. Flynn, J.; Slovic, P.; Mertz, C. Gender, Race, and Perception of Environmental Health Risks. Risk Anal. 1994, 14, 1101-1108. [CrossRef] [PubMed]

7. Lai, J.; Tao, J. Perception of Environmental Hazards in Hong Kong Chinese. Risk Anal. 2003, 23, 669-684. [PubMed]

8. Lupton, D. Risk; Routledge: New York, NY, USA, 1999; pp. 28-33.

9. O'Connor, R.E.; Bord, R.J.; Fisher, A. The curious impact of knowledge about climate change on risk perceptions and willingness to sacrifice. Risk Decis. Policy 1998, 3, 145-155. [CrossRef]

10. Siegrist, M. The influence of trust and perceptions of risks and benefits on the acceptance of gene technology. Risk Anal. 2000, 20, 195-204. [CrossRef] [PubMed]

11. Rosa, E.A.; Tuler, S.P.; Fischhoff, B.; Webler, T.; Friedman, S.M.; Sclove, R.E.; Shrader-Frechette, K.; English, M.R.; Kasperson, R.E.; Goble, R.L.; et al. Nuclear waste: Knowledge waste? Science (Washington) 2010, 329, 762-763. [CrossRef] [PubMed]

12. Slovic, P.; Flynn, J.H.; Layman, M. Perceived risk, trust, and the politics of nuclear waste. Science 1991, 254, 1603-1607. [CrossRef] [PubMed]

13. Bu, Y.M. Social amplification of risk: Framework and empirical research and implications. Study Pract. 2009, $12,120-125$.

14. Quan, S.-W.; Zeng, Y.-C.; Huang, B. Public Perception and Acceptance of Nuclear Power. Beijing Soc. Sci. 2012, 5, 55-60.

15. Earle, T.C.; Cvetkovich, G. Social Trust: Toward a Cosmopolitan Society; Greenwood Publishing Group: Westport, CT, USA, 1995.

16. Siegrist, M.; Cvetkovich, G.; Roth, C. Salient value similarity, social trust, and risk/benefit perception. Risk Anal. 2000, 20, 353-362. [CrossRef] [PubMed]

17. Bord, R.J.; O'Connor, R.E. Determinants of risk perceptions of a hazardous waste site. Risk Anal. 1992, 12, 411-416. [CrossRef]

18. Flynn, J.; Burns, W.; Mertz, C.K.; Slovic, F. Trust as a determinant of opposition to a high-level radioactive waste repository: Analysis of a structural model. Risk Anal. 1992, 12, 417-429. [CrossRef] 
19. Groothuis, P.A.; Miller, G. The role of social distrust in risk-benefit analysis: A study of the siting of a hazardous waste disposal facility. J. Risk Uncertain. 1997, 15, 241-257. [CrossRef]

20. Jungermann, H.; Pfister, H.R.; Fischer, K. Credibility, information preferences, and information interests. Risk Anal. 1996, 16, 251-261. [CrossRef]

21. SiegrisL, M.; CveLkovich, G. Perception of Hazards: The Role of Social Trust and Knowledge. Risk Anal. 2000, 20, 713-720. [CrossRef]

22. Sandman, P.M. Risk Communication: Facing Public Outrage. EPA J. 1987, 13, 21-22. [CrossRef]

23. Finucane, M.L.; Alhakami, A.; Slovic, P.; Johnson, S.M. The affect heuristic in judgments of risks and benefits. J. Behav. Decis. Mak. 2000, 13, 1-17. [CrossRef]

24. Epstein, S. Integration of the cognitive and psychodynamic unconscious. Am. Psychol. 1994, 49, 709-724. [CrossRef] [PubMed]

25. Loewenstein, G.F.; Weber, E.U.; Hsee, C.K.; Welch, N. Risk as feelings. Psychol. Bull. 2001, 127, $267-286$. [CrossRef] [PubMed]

26. Wang, J.; Qi, L.; Zhou, Q. Review of Research on Influencing Factor of the Public' Risk Perception. In Proceedings of the Conference on Psychology and Social Harmony (CPSH2012), Shanghai, China, 20-22 May 2012; pp. 485-488.

27. Midden, C. Credibility and risk communication. In Proceedings of the International Workshop on Risk Communication, Juelich, Germany, 17-20 October 1988; Volume 17, p. 21.

28. Lichtenthaler, U.; Lichtenthaler, E. A Capability-Based Framework for Open Innovation: Complementing Absorptive Capacity. J. Manag. Stud. 2009, 46, 1315-1338. [CrossRef]

29. Marsh, H.W.; Hocevar, D. Application of confirmatory factor analysis to the study of self-concept: First-and higher order factor models and their invariance across groups. Psychol. Bull. 1985, 97, 562. [CrossRef]

30. Wen, Z.; Hau, K.-T.; Chang, L. A Compar Ison Ofmoderator Andmed Iator and Their Applications. Acta Psychol. Sin. 2005, 37, 268-274.

(C) 2018 by the authors. Licensee MDPI, Basel, Switzerland. This article is an open access article distributed under the terms and conditions of the Creative Commons Attribution (CC BY) license (http:/ / creativecommons.org/licenses/by/4.0/). 